\title{
A Novel Solution Approach to a Priority-Slot-Based Continuous-Time Mixed Integer Nonlinear Programming Formulation for a Crude-Oil Scheduling Problem
}

Table S1. Objective Values for Solutions Obtained by Different Methods for Example 3

\begin{tabular}{|l|l|l|l|l|}
\hline & MILP solution & NLP solution & Optimality gap & Composition discrepancy \\
\hline The MILP/NLP method & 61.667 & No solution & N/A & Yes \\
\hline The proposed method & 59.583 & 59.583 & $0 \%$ & No \\
\hline
\end{tabular}

Table S2. Detailed Operations of the Obtained Solution by the Proposed Method for Example 3

\begin{tabular}{|c|c|c|c|c|}
\hline Priority-slot & Operation & Device & Oil types and amounts in device & Oil types and amounts delivered from a device \\
\hline 1 & $\mathrm{c} 1 \rightarrow \mathrm{d} 1$ & $\mathrm{c} 1$ & $\mathrm{C}(50)$ & $\mathrm{C}(50)$ \\
\hline 2 & $\mathrm{~s} 1 \rightarrow \mathrm{c} 1$ & $\mathrm{~s} 1$ & $\mathrm{~A}(41.167)$ & $\mathrm{A}(41.167)$ \\
\hline 3 & $\mathrm{~s} 1 \rightarrow \mathrm{c} 2$ & $\mathrm{~s} 1$ & $\mathrm{~A}(20.833)$ & $\mathrm{A}(20.833)$ \\
\hline 4 & $\mathrm{v} 1 \rightarrow \mathrm{s} 1$ & $\mathrm{v} 1$ & $\mathrm{~A}(100)$ & $\mathrm{A}(100)$ \\
\hline 5 & $\mathrm{~s} 2 \rightarrow \mathrm{c} 2$ & $\mathrm{~s} 2$ & $\mathrm{~B}(29.167)$ & $\mathrm{B}(29.167)$ \\
\hline 6 & $\mathrm{~s} 1 \rightarrow \mathrm{c} 1$ & $\mathrm{~s} 1$ & $\mathrm{~A}(45.833)$ & $\mathrm{A}(45.833)$ \\
\hline 7 & & $\mathrm{~A}(20.833)$ & $\mathrm{B}(29.167)$ \\
\hline 8 & $\mathrm{c} 2 \rightarrow \mathrm{d} 1$ & $\mathrm{c} 2$ & $\mathrm{~B}(29.167)$ & $\mathrm{D}(50)$ \\
\hline 9 & $\mathrm{~s} 1 \rightarrow \mathrm{c} 2$ & $\mathrm{~s} 1$ & $\mathrm{D}(50)$ & $\mathrm{A}(32.738)$ \\
\hline 10 & $\mathrm{~s} 2 \rightarrow \mathrm{c} 2$ & $\mathrm{~s} 2$ & $\mathrm{~A}(32.738)$ & $\mathrm{B}(45.833)$ \\
\hline 11 & $\mathrm{c} 1 \rightarrow \mathrm{d} 2$ & $\mathrm{v} 2$ & $\mathrm{~B}(45.833)$ & $\mathrm{B}(100)$ \\
\hline
\end{tabular}

Table S3. Solution Details for Example 4

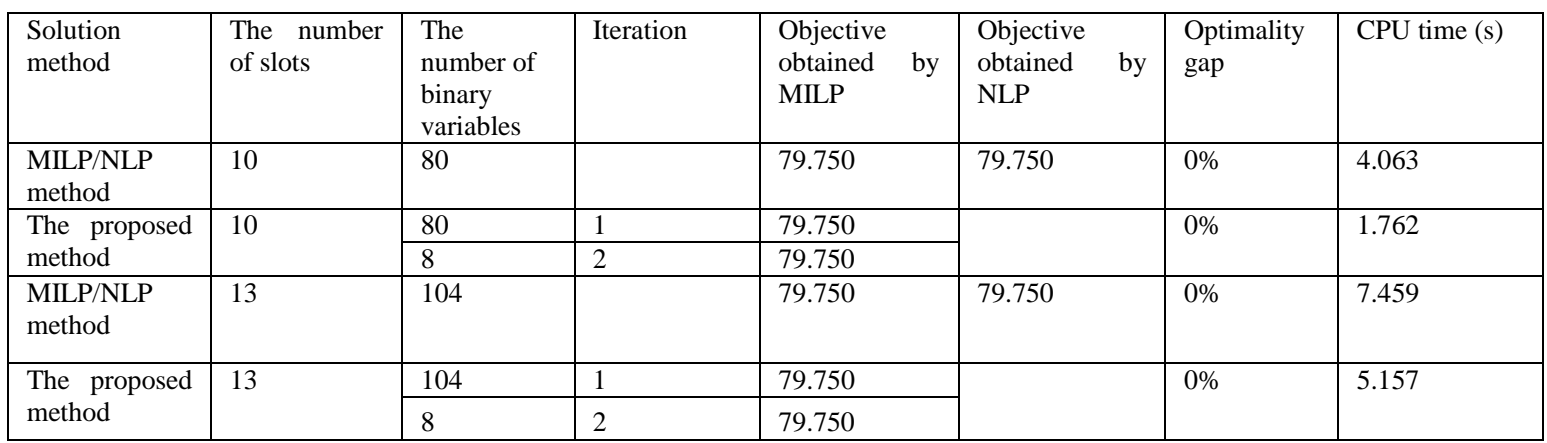


Table S4. Comparison on Performance between Different Methods with the Same Number of Slots for Examples 5, 6, and 7

\begin{tabular}{|c|c|c|c|c|c|c|c|}
\hline & & $\begin{array}{l}\text { The number } \\
\text { of slots }\end{array}$ & Iteration & $\begin{array}{l}\text { Objective } \\
\text { by MILP }\end{array}$ & $\begin{array}{l}\text { Objective } \\
\text { by NLP }\end{array}$ & $\begin{array}{l}\text { Optimality } \\
\text { gap }\end{array}$ & CPU time(s) \\
\hline \multirow[t]{2}{*}{ Example 5} & $\begin{array}{l}\text { MILP/NLP } \\
\text { method }\end{array}$ & 21 & & 101.175 & 101.175 & $0 \%$ & 187.375 \\
\hline & $\begin{array}{l}\text { The proposed } \\
\text { method }\end{array}$ & 21 & 1 & 101.175 & & $0 \%$ & 184.294 \\
\hline \multirow{10}{*}{ Example 6} & $\begin{array}{l}\text { MILP/NLP } \\
\text { method }\end{array}$ & 13 & & 87.400 & 84.500 & $3.32 \%$ & 16.275 \\
\hline & \multirow{4}{*}{$\begin{array}{l}\text { The proposed } \\
\text { method }\end{array}$} & \multirow[t]{4}{*}{13} & 1 & 87.400 & & \multirow{4}{*}{$1.79 \%$} & 13.391 \\
\hline & & & 2 & 86.329 & & & 0.505 \\
\hline & & & 3 & 84.329 & & & 0.132 \\
\hline & & & 4 & 85.836 & & & 0.045 . \\
\hline & $\begin{array}{l}\text { MILP/NLP } \\
\text { method }\end{array}$ & 21 & & 87.400 & 84.500 & $3.32 \%$ & 196.357 \\
\hline & \multirow{4}{*}{$\begin{array}{l}\text { The proposed } \\
\text { method }\end{array}$} & \multirow[t]{4}{*}{21} & 1 & 87.400 & & \multirow{4}{*}{$1.79 \%$} & 192.643 \\
\hline & & & 2 & 86.329 & & & 0.538 \\
\hline & & & 3 & 84.329 & & & 0.141 \\
\hline & & & 4 & 85.836 & & & 0.048 \\
\hline \multirow[t]{2}{*}{ Example 7} & $\begin{array}{l}\text { MILP/NLP } \\
\text { method }\end{array}$ & 19 & & 132.548 & 132.548 & $0 \%$ & 887.651 \\
\hline & $\begin{array}{l}\text { The proposed } \\
\text { method }\end{array}$ & 19 & 1 & 132.548 & & $0 \%$ & 884.482 \\
\hline
\end{tabular}

Table S5. Solution Details for Example 8

\begin{tabular}{|l|l|l|l|l|l|l|l|l|}
\hline Method & $\begin{array}{l}\text { The number } \\
\text { of slots }\end{array}$ & $\begin{array}{l}\text { The } \\
\text { number } \\
\text { of binary } \\
\text { variables }\end{array}$ & $\begin{array}{l}\text { Iteration } \\
\text { number }\end{array}$ & $t^{*}$ & $\begin{array}{l}\text { Objective } \\
\text { by MILP }\end{array}$ & $\begin{array}{l}\text { Objective } \\
\text { by NLP }\end{array}$ & $\begin{array}{l}\text { Optimality } \\
\text { gap }\end{array}$ & $\begin{array}{l}\text { CPU } \\
\text { time (s) }\end{array}$ \\
\cline { 1 - 8 } $\begin{array}{l}\text { MILP/NLP } \\
\text { method }\end{array}$ & 18 & 252 & & & 91.575 & $\begin{array}{l}\text { No } \\
\text { solution }\end{array}$ & & 127.358 \\
\hline $\begin{array}{l}\text { Proposed } \\
\text { one }\end{array}$ & 18 & 252 & 1 & 0 & 91.575 & & $0.6877 \%$ & 127.358 \\
\cline { 2 - 9 } & 126 & 2 & 1.1067 & 90.945 & & & 5.157 \\
\hline
\end{tabular}

Table S6. Solution Details for Example 9

\begin{tabular}{|l|l|l|l|l|l|l|l|l|}
\hline Method & $\begin{array}{l}\text { The number } \\
\text { of slots }\end{array}$ & $\begin{array}{l}\text { The } \\
\text { number } \\
\text { of binary } \\
\text { variables }\end{array}$ & $\begin{array}{l}\text { Iteration } \\
\text { number }\end{array}$ & $\mathrm{t}^{*}$ & $\begin{array}{l}\text { Objective } \\
\text { by MILP }\end{array}$ & $\begin{array}{l}\text { Objective } \\
\text { by NLP }\end{array}$ & $\begin{array}{l}\text { Optimality } \\
\text { gap }\end{array}$ & $\begin{array}{l}\text { CPU } \\
\text { time(s) }\end{array}$ \\
\hline $\begin{array}{l}\text { MILP/NLP } \\
\text { method }\end{array}$ & 13 & 182 & & & 8.569 & $\begin{array}{l}\text { No } \\
\text { solution }\end{array}$ & & 13.487 \\
\cline { 1 - 7 } $\begin{array}{l}\text { The } \\
\text { proposed } \\
\text { one }\end{array}$ & 13 & 182 & 1 & 0 & 83.569 & & $2.5045 \%$ & 13.487 \\
\cline { 2 - 5 } & 78 & 2 & 2.3748 & 81.476 & & & 2.325 \\
\hline
\end{tabular}


Table S7. Data for Example 10

\begin{tabular}{|c|c|c|c|}
\hline & Scheduling horizon & & 15 days \\
\hline Vessel & Arrival time & Composition & Amount of crude oil (Mbbl) \\
\hline Vessel 1 & 0 & $100 \% \mathrm{~A}$ & 500 \\
\hline Vessel 2 & 5 & $100 \% \mathrm{~B}$ & 500 \\
\hline Vessel 2 & 10 & $100 \% \mathrm{C}$ & 500 \\
\hline Storage tank & Capacity (Mbbl) & Initial composition & Initial amount of crude oil (Mbbl) \\
\hline Tank 1 & {$[100,900]$} & $100 \% \mathrm{D}$ & 200 \\
\hline Tank 2 & {$[100,1100]$} & $100 \% \mathrm{D}$ & 200 \\
\hline Tank 3 & {$[100,1100]$} & $100 \% \mathrm{E}$ & 200 \\
\hline Tank 4 & {$[100,1100]$} & $100 \% \mathrm{~F}$ & 200 \\
\hline Tank 5 & {$[100,900]$} & $100 \% \mathrm{H}$ & 300 \\
\hline Tank 6 & {$[100,900]$} & $100 \% \mathrm{H}$ & 600 \\
\hline charging tank & Capacity (Mbbl) & Initial composition & Initial amount of crude oil (Mbbl) \\
\hline Tank $1(\operatorname{mix} X)$ & {$[0,800]$} & $100 \% \mathrm{G}$ & 300 \\
\hline Tank $2(\operatorname{mix} Y)$ & {$[0,800]$} & $100 \% \mathrm{E}$ & 500 \\
\hline Tank 3 (mix Z) & {$[0,800]$} & $100 \% \mathrm{~F}$ & 300 \\
\hline Tank 4 (mix W) & {$[0,800]$} & $100 \% \mathrm{H}$ & 300 \\
\hline Crude oil type & Sulfur concentration & Gross margin $(\$ / \mathrm{bbl})$ & \\
\hline Crude oil A & 0.035 & 3 & \\
\hline Crude oil B & 0.085 & 5 & \\
\hline Crude oil C & 0.06 & 6.5 & \\
\hline Crude oil D & 0.02 & 3.1 & \\
\hline Crude oil E & 0.05 & 7.5 & \\
\hline Crude oil F & 0.08 & 3.17 & \\
\hline Crude oil G & 0.03 & 4.83 & \\
\hline Crude oil H & 0.095 & 6.33 & \\
\hline Crude mixture & Sulfur concentration & Demand (Mbbl) & \\
\hline Crude oil mix $\mathrm{X}$ & {$[0.025,0.035]$} & {$[600,600]$} & \\
\hline Crude oil mix Y & {$[0.045,0.065]$} & {$[600,600]$} & \\
\hline Crude oil mix $\mathrm{X}$ & {$[0.075,0.085]$} & {$[600,600]$} & \\
\hline Crude oil mix Y & {$[0.09,0.11]$} & {$[600,600]$} & \\
\hline Unloading flow rate & {$[0,500]$} & transportation flow rate & {$[0,500]$} \\
\hline Distillation flow rate & {$[20,500]$} & Number of distillations & 7 \\
\hline
\end{tabular}

Table S8. Solution Details for Example 10

\begin{tabular}{|c|c|c|c|c|c|c|c|c|}
\hline Method & $\begin{array}{l}\text { Priority-slots } \\
\text { number }\end{array}$ & $\begin{array}{l}\text { Number } \\
\text { of binary } \\
\text { variables }\end{array}$ & $\begin{array}{l}\text { Iteration } \\
\text { number }\end{array}$ & $\mathrm{t}^{*}$ & $\begin{array}{l}\text { Objective } \\
\text { by MILP }\end{array}$ & $\begin{array}{l}\text { Objective } \\
\text { by NLP }\end{array}$ & $\begin{array}{l}\text { Optimality } \\
\text { gap }\end{array}$ & $\begin{array}{l}\text { CPU } \\
\text { time(s) }\end{array}$ \\
\hline $\begin{array}{l}\text { MILP/NLP } \\
\text { method }\end{array}$ & 17 & 340 & & & 143.415 & $\begin{array}{l}\text { No } \\
\text { solution }\end{array}$ & & 746.381 \\
\hline \multirow{5}{*}{$\begin{array}{l}\text { The } \\
\text { proposed } \\
\text { one }\end{array}$} & \multirow{5}{*}{17} & 340 & 1 & 0 & 143.415 & & \multirow{5}{*}{$7.65 \%$} & 746.381 \\
\hline & & 240 & 2 & 1.0 & 140.1721 & & & 129.462 \\
\hline & & 120 & 3 & 6.0 & 138.4638 & & & 4.653 \\
\hline & & 60 & 4 & 11.0 & 136.9415 & & & 1.947 \\
\hline & & 40 & 5 & 11.32 & 132.4433 & & & 0.592 \\
\hline
\end{tabular}

\section{- APPENDIX}

\section{A. SOS mathematical model based on priority-slot for crude oil operations scheduling problems}

\section{Maximize}

$$
\sum_{i \in T} \sum_{r \in R_{D}} \sum_{v \in I_{r}} \sum_{c \in C} G_{c} \cdot V_{i v c}
$$

Subject to

Constraints of time for unloading oil from a vessel: Constraints (8)-(9) are used to enforce that only after 
the arrival of crude oil vessels to the dock, a vessel can be unloaded.

$$
\begin{aligned}
& S_{i v} \geq \underline{S_{v}} \cdot Z_{i v} \quad i \in T, v \in W_{U} \\
& \underset{v \in O_{i v}}{S_{v}} \leq S_{r} \quad r \in R_{V}, i \in T
\end{aligned}
$$

Time constraints: Constraints (10) and (11) restrict the beginning time, duration, and the ending time of operation $v$.

$$
\begin{aligned}
& E_{i v} \leq H \cdot Z_{i v} \quad i \in T, v \in W \\
& E_{i v}=S_{i v}+D_{i v} \quad i \in T, v \in W
\end{aligned}
$$

Cardinality constraints for unloading and distillation operations: Constraint (12) ensures that each vessel must be unloaded its cargo exactly once. In order to decrease the changeover cost of CDU switches, the total number of distillation operations is bounded by Constraint (13) using lower bound $\underline{N_{D}}$ and upper bound $\overline{N_{D}}$.

$$
\begin{aligned}
& \sum_{i \in T} \sum_{v \in O_{r}} Z_{i v}=1 \quad r \in R_{V} \\
& \underline{N_{D}} \leq \sum_{i \in T} \sum_{v \in W_{D}} Z_{i v} \leq \overline{N_{D}}
\end{aligned}
$$

Unloading sequence constraints: Constraints (14)-(15) define the unloading sequence of crude oil vessels that must be unloaded in order of their arrival time to the dock.

$$
\begin{aligned}
& \sum_{i \in T} \sum_{v \in O_{r_{1}}} E_{i v} \leq \sum_{i \in T} \sum_{v \in O_{r_{2}}} S_{i v} r_{1}, r_{2} \in R_{V}, r_{1}<r_{2} \\
& \sum_{j \in T, j<i} \sum_{v \in O_{r_{1}}} Z_{j v} \leq \sum_{j \in T, j \leq i} \sum_{v \in O_{r_{2}}} S_{i v} \quad i \in T, r_{1}, r_{2} \in R_{V}, r_{1}<r_{2}
\end{aligned}
$$

Continuous distillation constraint: The continuousness of CDU distillation is ensured by Constraint (16). Since each CDU can be charged by only one charging tank, continuous distillation can be defined by the total distillation time equating the whole scheduling horizon $H$.

$\sum_{i \in T} \sum_{v \in I_{r}} D_{i v}=H \quad r \in R_{D}$

Assignment constraint: Constraint (17) enforces that at most one operation must be assigned to each priority-slot. 


$$
\sum_{v \in W} Z_{i v} \leq 1 \quad i \in T
$$

Symmetry breaking constraint: Constraint (18) is used to eliminate non-occupancy of a priority-slot for avoiding slot redundancy.

$\sum_{v \in W} Z_{i v} \geq 1, \quad i \in T$

Non-overlapping constraints: Constraints (19)-(21) ensure that two operations $v_{1}$ and $v_{2}$ must not be simultaneously fulfilled.

$$
\begin{gathered}
E_{i_{1} v_{1}}+E_{i_{1} v_{2}} \leq S_{i_{2} v_{1}}+S_{i_{2} v_{2}}+H \cdot\left(1-Z_{i_{2} v_{1}}-Z_{i_{2} v_{2}}\right) \\
i_{1}, i_{2} \in T, i_{1}<i_{2}, v_{1}, v_{2} \in W, N O_{v_{1} v_{2}}=1 \\
E_{i_{1} v_{1}} \leq S_{i_{2} v_{2}}+H \cdot\left(1-Z_{i_{2} v_{2}}\right) i_{1}, i_{2} \in T, i_{1}<i_{2}, v_{1}, v_{2} \in W, N O_{v_{1} v_{2}}=1 \\
E_{i_{1} v_{2}} \leq S_{i_{2} v_{1}}+H \cdot\left(1-Z_{i_{2} v_{1}}\right) i_{1}, i_{2} \in T, i_{1}<i_{2}, v_{1}, v_{2} \in W, N O_{v_{1} v_{2}}=1
\end{gathered}
$$

Constraints (22)-(23) bound crude oil volume transferred by operation $v$ using lower bound $\underline{V}_{v}^{t}$ and upper

$$
\begin{gathered}
\text { one } \overline{V_{v}^{t}} \cdot \\
V_{i v}^{t} \leq \overline{V_{v}^{t}} \cdot Z_{i v} \quad i \in T, v \in W \\
V_{i v}^{t} \geq \underline{V_{v}^{t}} \cdot Z_{i v} \quad i \in T, v \in W
\end{gathered}
$$

Constraints (24)-(26) enforce material balance for transferring operation.

$$
\begin{aligned}
V_{i v}^{t} & =\sum_{c \in C} V_{i v c} \quad i \in T, v \in W \\
L_{i r c} & =L_{0 r c}+\sum_{j \in T, j<i} \sum_{v \in I_{r}} V_{i v c}-\sum_{j \in T, j<i} \sum_{v \in O_{r}} V_{i v c} i \in T, r \in R, c \in C \\
L_{i r}^{t} & =\sum_{c \in C} L_{i r c} \quad i \in T, v \in W
\end{aligned}
$$

Constraints (27) bound the flowrate by $F R_{v}$ and $\overline{F R_{v}}$.

$\underline{F R_{v}} \cdot D_{i v} \leq V_{i v}^{t} \leq \overline{F R_{v}} \cdot D_{i v} \quad i \in T, v \in W$

Property constraint: Constraint (28) bounds property $k$ of the blender transferred by operation $v$, and calculates property $k$ of the blender from property $x_{c k}$ of crude oil $c$ by the assumption that the mixing procedure is linear. 
$\underline{x_{v k}} \cdot V_{i v}^{t} \leq \sum_{c \in C} x_{c k} V_{i v c} \leq \underline{x_{v k}} \cdot V_{i v}^{t} \quad i \in T, v \in W, k \in K$

Constraints (29)-(32) ensure material balance for inventory of tanks.

$\underline{L_{r}^{t}} \leq L_{i r}^{t} \leq \overline{L_{r}^{t}} \quad i \in T, r \in R_{S} \cup R_{C}$

$0 \leq L_{i r c} \leq \overline{L_{r}^{t}} \quad i \in T, c \in C, r \in R_{S} \cup R_{C}$

$\underline{L_{r}^{t}}=L_{0 r}^{t}+\sum_{i \in T} \sum_{v \in I_{r}} V_{i v}^{t}-+\sum_{i \in T} \sum_{v \in O_{r}} V_{i v}^{t} \leq \overline{L_{r}^{t}} \quad r \in R_{S} \cup R_{C}$

$0 \leq L_{0 r c}+\sum_{i \in T} \sum_{v \in I_{r}} V_{i v c}-+\sum_{i \in T} \sum_{v \in O_{r}} V_{i v c} \leq \overline{L_{r}^{t}} \quad r \in R_{S} \cup R_{C}, c \in C$

Constraint (33) is a demand constraint, which define lower and upper bounds, $\underline{D_{r}}$ and $\overline{D_{r}}$, to restrict the total volume of feedstock charged by each charging tank during the whole scheduling horizon $H$.

$\underline{D_{r}} \leq \sum_{i \in T} \sum_{v \in O_{r}} V_{i v}^{t} \leq \overline{D_{r}} \quad r \in R_{C}$ 